\title{
Água ozonizada: uma nova proposta na desinfecção de superfícies em salas de cirurgias ortopédicas
}

\author{
Ozonized water: a new proposal for surface disinfection in orthopedic operating rooms \\ Agua ozonizada: una nueva propuesta para la desinfección de superficies en \\ quirófanos ortopédicos
}

Fernanda da Silva Lima ${ }^{1 *}$, Monica Karla Vojta Miranda ${ }^{1}$, Jociléia da Silva Bezerra ${ }^{2}$, Mariane Santos Ferreira $^{1}$, Sheila Mara Bezerra de Oliveira ${ }^{1}$, Lívia de Aguiar Valentim ${ }^{1}$, Leandro Procópio Alves ${ }^{3}$, Andreza Alves Pessôa ${ }^{1}$, Irinéia de Oliveira Bacelar Simplício¹.

\section{RESUMO}

Objetivo: Analisar a eficácia da água ozonizada na desinfecção de superfícies de mesas cirúrgicas ortopédicas de um hospital público na Região do Baixo Amazonas. Métodos: Estudo exploratório-descritivo, realizado em Santarém, Pará, com superfícies de mesas cirúrgicas para a amostragem. Analisaram-se as superfícies após desinfecção com água ozonizada através do ensaio Adenosina Trifosfato Bioluminescência (ATP), considerada eficaz quando o registro era inferior a 250 Unidades de Luz Relativa (RLUs). Os dados foram analisados no software IBM SPSS Statistics e através do teste qui-quadrado. O estudo foi aprovado por Comitê de Ética em Pesquisa (CEP) sob o número de CAAE 39785220.4.0000.5168. Resultados: A amostragem compreendeu 24 superfícies de mesas cirúrgicas desinfetadas com a água ozonizada. Os valores de até $10 \mathrm{RLU}$ somou o maior número de registros, com $83,3 \%$ (20), enquanto que valores de 11-20 RLU apresentaram 12,5\% (3), e 21-30 RLU indicou 4,2\% (1). O método utilizado para avaliação da desinfecção não evidenciou contaminação em $100 \%$ das superfícies analisadas. Conclusão: Os valores obtidos de RLUs a partir do ensaio de bioluminescência de ATP evidenciaram que o uso da água ozonizada em superfícies de salas cirúrgicas ortopédicas é uma proposta eficaz para desinfecção em ambiente nosocomial.

Palavras-chave: Desinfecção, Limpeza, Superfícies, Água ozonizada, Cirurgia ortopédica.

\begin{abstract}
Objective: To analyze the effectiveness of ozonized water in the disinfection of orthopedic surgical table surfaces in a public hospital in the Baixo Amazonas region. Methods: Exploratory-descriptive study, carried out in Santarém, Pará, with surgical table surfaces for sampling. Surfaces were analyzed after disinfection with ozonized water using the Adenosine Triphosphate Bioluminescence (ATP) assay, considered effective when the recording was less than 250 Relative Light Units (RLUs). Data were analyzed using the IBM SPSS Statistics software and using the chi-square test. The study was approved by the Research Ethics Committee (CEP) under the number of CAAE 39785220.4.0000.5168. Results: The sampling comprised 24 surfaces of surgical tables disinfected with ozonized water. Values of up to $10 \mathrm{RLU}$ accounted for the largest number of records, with $83.3 \%$ (20), while values of $11-20 \mathrm{RLU}$ had $12.5 \%$ (3), and $21-30 \mathrm{RLU}$ indicated $4.2 \%$ (1). The method used to assess disinfection did not show contamination in $100 \%$ of the surfaces analyzed. Conclusion: The values of RLUs obtained from the ATP bioluminescence assay showed that the use of ozonized water on surfaces of orthopedic operating rooms is an effective proposal for disinfection in a nosocomial environment.
\end{abstract}

Keywords: Disinfection, Cleaning, Surfaces, Ozonized water, Orthopedic surgery.

\footnotetext{
1 Universidade do Estado do Pará (UEPA), Santarém - PA. *E-mail: fernandalima_sl@outlook.com

2 Escola Superior de Teologia, Santarém - PA.

${ }^{3}$ Universidade Anhembi Morumbi, São José dos Campos - SP.
} 


\section{RESUMEN}

Objetivo: Analizar la efectividad del agua ozonizada en la desinfección de superficies de mesas quirúrgicas ortopédicas en un hospital público de la región del Baixo Amazonas. Métodos: Estudio exploratorio descriptivo, realizado en Santarém, Pará, con superficies de mesa quirúrgica para muestreo Las superficies fueron analizadas después de la desinfección con agua ozonizada a través del ensayo de Bioluminiscencia Adenosina Trifosfato (ATP), considerado efectivo cuando el registro era inferior a 250 Unidades de Luz Relativa (RLU). Los datos se analizaron con el software IBM SPSS Statistics y con la prueba de chi-cuadrado. El estudio fue aprobado por el Comité de Ética en Investigación (CEP) bajo el número de CAAE 39785220.4.0000.5168. Resultados: El muestreo comprendió 24 superficies de mesas quirúrgicas desinfectadas con agua ozonizada. Los valores de hasta $10 \mathrm{RLU}$ representaron el mayor número de registros, con 83,3\% (20), mientras que los valores de 11-20 RLU tenían 12,5\% (3), y 21-30 RLU indicaron 4,2\% (1). El método utilizado para evaluar la desinfección no mostró contaminación en el $100 \%$ de las superficies analizadas. Conclusión: Los valores de RLU obtenidos del ensayo de bioluminiscencia de ATP mostraron que el uso de agua ozonizada en superficies de quirófanos ortopédicos es una propuesta eficaz para la desinfección en un ambiente nosocomial.

Palabras clave: Desinfección, Limpieza, Superficies, Agua ozonizada, Cirugía ortopédica.

\section{INTRODUÇÃO}

O controle de Infecções Relacionadas à Assistência à Saúde (IRAS) está intimamente associado a limpeza e desinfecção do ambiente hospitalar (ARKEL AV, et al., 2020). Evidências científicas indicam que as superfícies hospitalares podem ser veículos de transmissão e até mesmo reservatórios de diversos patógenos associados a assistência à saúde, necessitando um método eficaz para reduzir a disseminação de microrganismos (DRESCH F, et al., 2018; FURLAN MC, et al., 2019).

Nesse sentido, o Centro Cirúrgico (CC) é considerado um ambiente de alto risco, onde as Infecções do Sítio Cirúrgico (ISC) destacam-se como um dos principais riscos à segurança do paciente nos serviços de saúde no Brasil, ocupando a terceira posição entre as IRAS (SPRUCE L, 2020; NASCIMENTO EAS, et al., 2021; AGÊNCIA NACIONAL DE VIGILÂNCIA SANITÁRIA (ANVISA), 2017a). Segundo Haque M, et al. (2018), os pacientes ortopédicos destacam-se com maior risco de ISC, o que demanda rigor em todo o processo perioperatório.

As infecções ligadas aos procedimentos ortopédicos são consideradas de gravidade elevada, visto que envolvem o uso de materiais de implantes, potencializando o risco do processo infeccioso que pode acarretar em sérias complicações ao paciente (SANTOS PVF, et al., 2017). Nesse aspecto, os fatores de risco associados à infecção ortopédica podem estar relacionados as condições do paciente, à execução da técnica cirúrgica e ao ambiente onde será realizado o procedimento cirúrgico (SILVA EN, et al., 2021).

Partindo dessa primíssima, para o controle das infecções cirúrgicas e estabelecimento de medidas de prevenção de danos relacionados a procedimentos e/ou das estruturas físicas de unidades de assistência à saúde, torna-se imperativo a execução da limpeza com eficácia em todos os equipamentos e superfícies do ambiente hospitalar (ANVISA, 2017b; ROBAKOWSKA M, et al., 2021). Ressalta-se a importância da realização de estudos para identificar procedimentos de limpeza e desinfecção eficazes no ambiente nosocomial (SOUZA MGA, et al., 2021).

Diante do exposto, variadas substâncias têm sido utilizadas para essa finalidade, incluindo o uso do ozônio $\left(\mathrm{O}_{3}\right)$, considerado um desinfetante com atividade antimicrobiana de amplo espectro, tornando-o uma escolha ideal para a limpeza de superfícies hospitalares (FREITAS LA, et al., 2019, SATO Y, et al., 2019; CAETANO $\mathrm{MH}$, et al., 2021). Segundo Wei $\mathrm{C}$, et al. (2017), o $\mathrm{O}_{3}$ é um gás solúvel em água, instável e incolor formado pelo agrupamento de três átomos de oxigênio que pode ser utilizado na forma gasosa ou aquosa promovendo alto nível de desinfecção, pois possui atividade microbicida, em que bactérias e vírus são sensíveis a sua ação, isso devido ao poder de ataque direto aos microrganismos com a oxidação do material biológico (BOTELHO-ALMEIDA TS, et al., 2018; WOLLHEIM C, et al., 2020). 
Atualmente a água ozonizada tornou-se um método alternativo na desinfecção de superfícies em ambientes hospitalares e tem sido indicada por possuir excelentes propriedades antimicrobianas, sendo obtida após o processo de ozonização, borbulhamento de ozônio na água (SÁNCHEZ GM, 2019), em que baixas concentrações e curta duração de ação do ozônio são necessárias para eliminar os microrganismos (DEMIR F e ATGUDEN A, 2016).

Acrescenta-se ao exposto o uso do ensaio Adenosina Trifosfato Bioluminescência (ATP) para validação de limpeza e desinfecção de superfícies com a água ozonizada. Dados de pesquisas publicadas recentemente descrevem o uso de ensaios baseados na detecção de ATP com resultados expressos em Unidades Relativas de Luz (RLU, da sigla em inglês Relative Light Units), que representam a quantidade de matéria orgânica presente nas superfícies ambientais (SANNA T, et al., 2018; ALVIM AL, et al., 2019; MASIA MD, et al., 2021).

Considerando o entendimento da importância que o ambiente terapêutico exerce na transmissão de microrganismos, o estudo foi realizado com o objetivo de analisar a eficácia da água ozonizada na desinfecção de superfícies de mesas cirúrgicas ortopédicas de um hospital público do Baixo Amazonas.

\section{MÉTODOS}

\section{Delineamento do Estudo}

Trata-se de um estudo exploratório-descritivo com uma abordagem quantitativa realizado no segundo semestre de 2020, em duas Salas Operatórias (SO) de cirurgias ortopédicas em um hospital público na região do Baixo Amazonas, município de Santarém, Pará, Brasil. A instituição atende, exclusivamente, pacientes do Sistema Único de Saúde (SUS) e se destaca na região como referência no tratamento ao paciente ortopédico de média e alta complexidade. Em média, são realizadas sete cirurgias eletivas por dia.

Para a amostragem, em cada uma das SO haviam duas mesas cirúrgicas de aço inoxidável, com superfícies de 45/1,20 cm e 60/1,20 cm, utilizadas para a colocação de instrumentais estéreis na realização de procedimentos cirúrgicos. Todos os procedimentos cirúrgicos ortopédicos realizados durante a coleta de dados foram classificados como limpos e uma média de quatro pessoas (variação: 3-5) constituiram a equipe cirúrgica.

O protocolo de limpeza e desinfecção com água ozonizada e aquisição das amostras pelo ensaio Adenosina Trifosfato Bioluminescência foi aplicado após o paciente deixar a sala operatória. Todas as SO tinham as mesmas características estruturais e aplicavam o mesmo protocolo operativo de práticas de limpeza. Durante a coleta de dados foram realizados 12 procedimentos cirúrgicos, com o total de 24 amostras das superficies de mesas cirúrgicas avaliadas.

\section{Aquisição de água ozonizada}

A água ozonizada foi preparada através de um gerador de ozônio (OzonLife, Medical Systems, Brasil) por meio do efeito corona, incorporando uma massa de gás/água na concentração de $2,7 \mathrm{mg} / \mathrm{L}$ de ozônio (Gráfico 1). No efeito corona, as moléculas de oxigênio recebem descargas elétricas de alta energia, o que ocasiona sua divisão em átomos livres que reagem com outras moléculas de oxigênio, gerando as moléculas triatômicas de $\mathrm{O}_{3}$ (DOBEIC M, 2017).

O processo ocorreu dentro de uma capela de fluxo laminar e o gerador foi conectado a um cilindro de oxigênio sob um fluxo contínuo de $1 / 8 \mathrm{~L} / \mathrm{min}$, interligado a um difusor de gás imerso em $480 \mathrm{ml}$ de água destilada em uma temperatura de $8^{\circ} \mathrm{C}$, com 2 cubos de gelo de $10 \mathrm{ml}$ cada produzidos com água ozonizada em um recipiente de vidro, por 15 minutos. Foi executado através de um difusor em aço inox (Nesia, China), na forma de um cilindro, medindo $2,6 \mathrm{~cm}$ de altura, $1,3 \mathrm{~cm}$ de diâmetro e microfuros de $0,5-2 \mu \mathrm{m}$. Posteriormente foi transferida para um borrifador de vidro contendo gelo de água ozonizada para manter a temperatura desejada. $\mathrm{O}$ transporte da água ozonizada para as $\mathrm{SO}$ ocorreu por meio de uma caixa térmica para uso imediato. 
Gráfico 1 - Curva de concentração do ozônio.

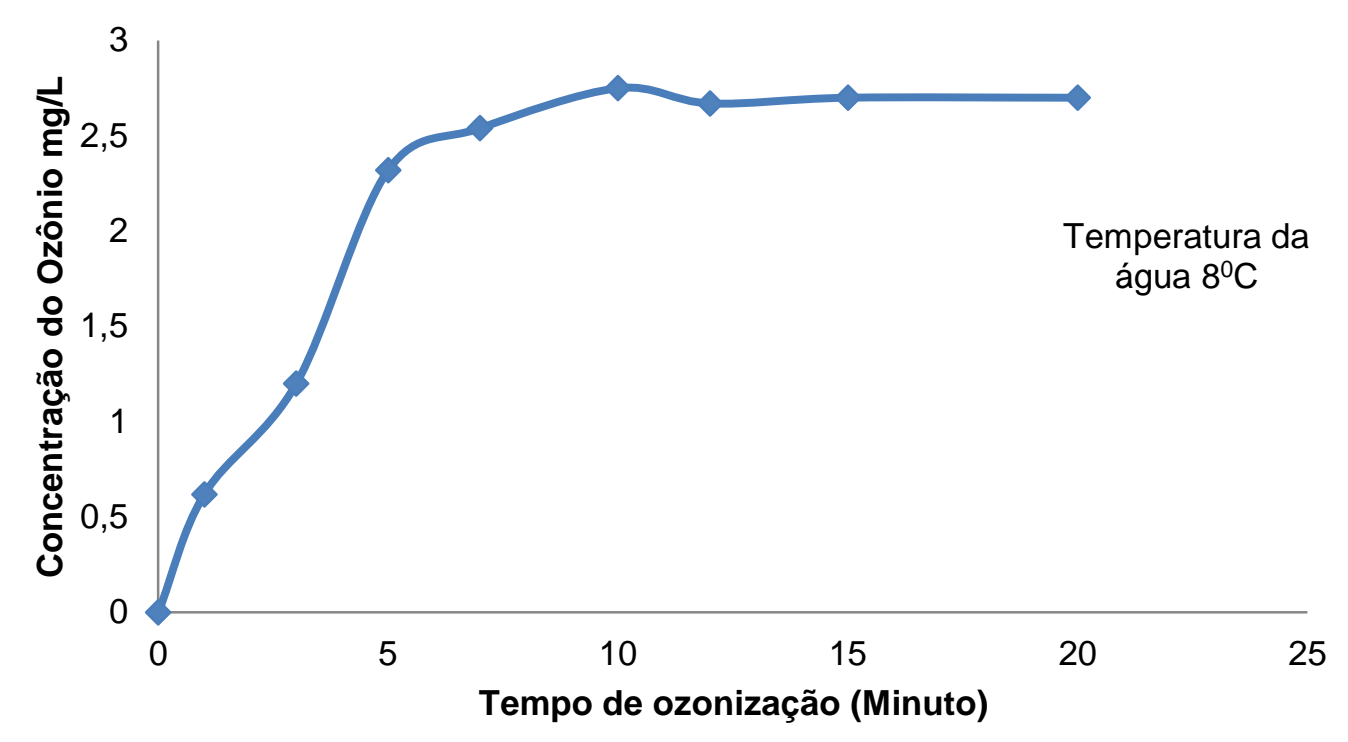

Fonte: Lima FS, et al., 2021.

\section{Protocolo de desinfecção com água ozonizada e aquisição das amostras pela Bioluminescência de Trifosfato de Adenosina (ATP)}

A água ozonizada foi borrifada na superfície das mesas cirúrgicas de forma horizontal e unidirecional, aguardou-se por 2 minutos. Em seguida foi realizada a remoção da água com compressa limpa para completa secagem das superfícies. Após o procedimento de desinfecção, delimitou-se a área de coleta (centro da mesa) com um campo fenestrado de manta de Spunbond, Meltblown, Spunbond (SMS) estéril, com um fenestro com área de $100 \mathrm{~cm}^{2}$. A aquisição da amostra foi por meio de esfregaço com swab pertencente ao kit $3 \mathrm{M}^{\mathrm{TM}}$ Clean Trace ${ }^{\mathrm{TM}}$ ATP System, Código HB004116271, com movimentos horizontais em forma de zig zag por um ângulo de $30^{\circ} \mathrm{C}$ na superfície da mesa, com intervalos de $5 \mathrm{~mm}$, no sentido diagonal, com objetivo de padronização do processo de quantificação do material.

A amostra foi agitada manualmente por 5 segundos e introduzida na cubeta de reação de bioluminescência de ATP. Durante esse processo, o ATP coletado reagiu com a luciferina na presença da luciferase com liberação de energia na forma de luz (bioluminescência). A cubeta de reação foi colocada no luminômetro, que forneceu uma leitura digital da quantidade de luz detectada e quantificada em Unidades de Luz Relativa (RLUs).

\section{Aspectos Éticos}

O estudo foi aprovado pelo Comitê de Ética em Pesquisa (CEP) da Universidade do Estado do Pará, CAAE 39785220.4.0000.5168, sob o parecer de número 4.743.235. O desenvolvimento do estudo atendeu às normas nacionais e internacionais de ética em pesquisa.

\section{Análise Estatística}

Os dados obtidos foram registrados em planilha no Excel (Microsoft Office, Microsoft Corporation, Redmond, WA, EUA) e resumidos com frequências absolutas e relativas (percentuais), com média e mediana. As análises foram realizadas por estatística descritiva com auxílio do software Statistical Package for Social Science (SPSS; IBM Corporotion, versão 26) e teste qui-quadrado. Os dados obtidos pelo ensaio de ATP-bioluminescência (RLU) na pesquisa concentraram-se em valores mínimos de variabilidade. Para manter o rigor e a cientificidade da pesquisa, todos os procedimentos deste estudo foram tratados com nível de significância de 5\%, para um valor de $p<0,05$. 


\section{RESULTADOS}

A amostragem compreendeu 24 amostras registradas em RLUs a partir do ensaio de ATPbioluminescência, com média geométrica e mediana de 6,95 RLU e 4,5 RLU, respectivamente. Para avaliar o processo de desinfecção e limpeza das superfícies de mesas cirúrgicas com água ozonizada foram verificadas algumas variáveis das salas operatórias que podem influenciar na qualidade da limpeza das superfícies das mesas cirúrgicas como, "tempo de cirurgia", "temperatura do ambiente", "umidade relativa do ar", e "tipo de cirurgia". Assim, os resultados foram expressos da seguinte forma:

\section{Tempo de Cirurgia}

Foram registrados o tempo de início e término das cirurgias para verificar a duração do procedimento cirúrgico nas salas operatórias. Observou-se que mais da metade dos procedimentos foram realizados de 60 até 120 minutos, $16(66,67 \%) ; 6(8,33 \%)$ foram realizados em até 60 minutos; e além disso, apenas 2 procedimentos foram realizados entre 120 e 180 minutos, (25\%) (Tabela 1).

Tabela 1 - Variáveis avaliadas na desinfecção de superfícies de mesas cirúrgicas com água ozonizada em um hospital público na Região do Baixo Amazonas, 2020.

\begin{tabular}{|c|c|c|}
\hline Variáveis & $\mathbf{N}$ & $\%$ \\
\hline \multicolumn{3}{|l|}{ Tempo de cirurgia } \\
\hline$<60$ min. & 6 & 8,33 \\
\hline $60-120 \mathrm{~min}$. & 16 & 66,67 \\
\hline $120-180 \mathrm{~min}$ & 2 & 25 \\
\hline \multicolumn{3}{|c|}{ Temperatura ambiente } \\
\hline $20-20,5$ & 12 & 50 \\
\hline $20,6-21,5$ & 8 & 33,33 \\
\hline $21,6-22,5$ & 4 & 16,67 \\
\hline \multicolumn{3}{|c|}{ Umidade relativa do ar } \\
\hline$<50 \%$ & 12 & 50 \\
\hline $51-60 \%$ & 12 & 50 \\
\hline \multicolumn{3}{|l|}{ Tipo de cirurgia } \\
\hline Média complexidade & 6 & 25 \\
\hline Alta complexidade & 18 & 75 \\
\hline Total & 24 & 100 \\
\hline
\end{tabular}

Fonte: Lima FS, et al., 2022.

\section{Temperatura do ambiente}

Em relação a temperatura ambiente nas $\mathrm{SO}$, os dados analisados demonstraram que há a prevalência de $20^{\circ} \mathrm{C}$ a $20,5^{\circ} \mathrm{C}$, com $12(50 \%)$ das amostras; os valores entre $21,6^{\circ} \mathrm{C}$ a $22,5^{\circ} \mathrm{C}$ foi o total de $4(16,67 \%)$; e os resultados de $20,6^{\circ} \mathrm{C}$ a $21,5^{\circ} \mathrm{C}$ foram registrados em 8 (33,33\%) dos procedimentos cirúrgicos realizados (Tabela 1).

\section{Umidade relativa do ar}

De acordo com a umidade relativa do ar, nota-se que $12(50 \%)$ dos procedimentos cirúrgicos foram realizados em SO com umidade < 50\%, assim como também 12 (50\%) foram realizados em 51 a $60 \%$ (Tabela 1).

\section{Tipo de cirurgia}

No que diz respeito as cirúrgias ortopédicas realizadas nas salas operatórias, foram classificadas em dois tipos, de média e alta complexidade, sendo que os dados analisados demonstraram um número expressivo de cirurgias de alta complexidade, representando 18 (75\%), enquanto que as cirurgias de média complexidade foram apenas $6(25 \%)$. Pôde-se observar os valores significativos de $\mathrm{p}(p=0,0247)$ associado ao tipo de cirurgia (Tabela 1). 
Em relação a avaliação da eficácia do uso da água ozonizada para a desinfecção, os principais resultados desse estudo apontaram valores significativos $(p=0,0001)$ na distribuição de RLU das 24 superfícies de mesas cirúrgicas avaliadas. Destacou-se os valores de até $10 \mathrm{RLU}$, que somou o maior número de registros, com $83,3 \%$ (20), enquanto que valores de $11-20$ RLU apresentaram $12,5 \%$ (3), e foram apenas $4,2 \%$ (1) os valores de 21-30 RLU (Tabela 2).

Tabela 2- Distribuição dos valores de ATP- bioluminescência (RLU) na desinfecção de superfícies de mesas cirúrgicas com água ozonizada, n=24, em um hospital público na Região do Baixo Amazonas, 2020.

\begin{tabular}{lccc}
\hline Variável & N & $\%$ & $\boldsymbol{P}$ \\
\hline RLU & & & $<0,0001$ \\
\hline$<10$ & 20 & 83.33 & \\
$11-20$ & 3 & 12.5 & \\
$21-30$ & 1 & 4.17 & \\
$31-40$ & 0 & 0 & \\
\hline Total & $\mathbf{2 4}$ & $\mathbf{1 0 0}$ & \\
\hline
\end{tabular}

Legenda: Unidade de Luz Relativa (RLU).

Fonte: Lima FS, et al., 2021.

\section{DISCUSSÃO}

O crescimento do número de cirurgias ortopédicas tem ocorrido nos últimos anos, com isso aumenta-se a preocupação com as ISC (SILVA EN, et al., 2021). Nesse sentido, vários parâmetros podem ser responsáveis por causar infecção em um CC (GIROTRA R, 2020). Nas SO devem ser garantido elevados padrões de limpeza e desinfecção, pois as superfícies podem representar um reservatório de microrganismos patogênicos (REZENDE C, et al., 2018).

Bruce $N$, et al. (2007) explanou o risco de infecções associadas à alta umidade do ambiente, documentando um aumento de infecções quando as SO apresentaram alta umidade, além de suprimentos estéreis e instrumentos úmidos no $\mathrm{CC}$, assim destacou que a umidade relativa para salas de cirurgia deve ser de $30-60 \%$, valores que vão de encontro com os resultados apresentados nessa atual pesquisa, visto que os resultados registrados são menores que $60 \%$.

Um estudo realizado por Liu Z, et al. (2021) também avaliou parâmetros ambientais de uma SO, como a velocidade de fornecimento de ar e temperatura ambiente. $O$ autor abordou que à medida que a temperatura ambiente aumentava, o número de partículas na área cirúrgica também aumentou, sendo a faixa de temperatura adequada com valores entre 18 a $24{ }^{\circ} \mathrm{C}$, para o paciente não apresentar risco de hipotermia e os profissionais de saúde apresentarem conforto térmico. Assim, os valores corroboram com os dados dessa pesquisa, visto que a média geométrica das temperaturas registradas foi de $20,8 \stackrel{\circ}{ } \mathrm{C}$.

Percebe-se que o tempo de cirurgia está diretamente ligada à ocorrência de ISC. Ravi B, et al. (2019), concluiram que os pacientes ortopédicos com uma duração cirúrgica 'longa' ( $\geq 100 \mathrm{~min}$ ) tiveram uma taxa maior de infecção. Outrossim, destacou que pacientes mais complexos, com comorbidades, necessitam de maior tempo cirúrgico, além de que o aumento da probabilidade de ISC, seja diretamente ou de instrumentos contaminados secundariamente. Desse modo, nessa atual pesquisa prevaleceu o maior número de pacientes com procedimentos cirúrgicos ortopédicos de alta complexidade, o que pode ser pressumido que devem ser assistidos por maior tempo na sala operatória, visto que a média de tempo para a maioria dos procedimentos cirúrgicos realizados foi de 120 minutos.

A verificação da eficácia da água ozonizada na desinfecção de superfícies de mesas cirúrgicas através da quantidade de matéria orgânica (níveis de ATP) e os métodos utilizados contribuem para a qualidade da limpeza e desinfecção de superfícies em ambientes hospitalares. Os procedimentos de limpeza e desinfecção nosocomiais são essenciais para a redução da disseminação de microrganismos, prevenindo infecções associadas a assistência à saúde (FROTA OP, et al., 2020, NASCIMENTO EAS, et al., 2021). 
O uso de ozônio $\left(\mathrm{O}_{3}\right)$ como desinfetante para controle antimicrobiano é uma opção efetiva e de baixocusto (LOPES MS, et al., 2015; CAETANO MH, et al., 2021). Feng L, et al. (2018) inferem que o ozônio aquoso penetra células e inativa enzimas de microrganismos, inibe genes e degrada os materiais genéticos, o levando à morte celular. Segundo Nascente EP, et al. (2019), o ozônio altera a polaridade da superfície bacteriana, onde os íons da água ozonizada encontram atração com a parede celular, atuando na ruptura celular.

Martins RB, et al. (2020) encontraram significativa redução do potencial infectante de um vírus após sua exposição a água ozonizada por 1 minuto, sugerindo seu uso para desinfecção de superfícies. $O$ efeito antimicrobiano do $\mathrm{O}_{3}$ é evidenciado, por ter propriedade bactericida, fungicida e virucida, pois bloqueiam os receptores virais e elimina as células contaminadas por estes microrganismos. Além disso, tem capacidade de eliminar protozoários, por causa de seu elevado e comprovado poder desinfetante e esterilizante (TORMIN SC, et al., 2016; LUIGI C, 2020).

Adicionalmente, nessa atual pesquisa levamos em consideração o valor de 250 RLU na mensuração do ensaio de bioluminescência de ATP, sendo como padrão de referência para a validação da limpeza e desinfecção de superficies das mesas cirúrgicas com a água ozonizada, de acordo com instruções do fabricante do luminômetro $3 \mathrm{M}^{\mathrm{TM}}$ CleanTrace ${ }^{\mathrm{TM}}$ ATP System utilizado na coleta de dados e informações de publicações recentes (SANNA T, et al., 2018, FURLAN MC, et al., 2019).

Caetano MH, et al. (2021), realizou uma pesquisa em superfícies de dez salas de laboratórios, e destacou a atividade antimicrobiana do gás $\mathrm{O}_{3}$ com registros de redução de patógenos. Portanto, a realização deste atual estudo vem expandir o que já se sabe sobre a água ozonizada, uma vez que os resultados mostram valores de RLU detectados muito baixos após o seu uso, mostrando em 100\% das coletas não haver contaminação microbiana nas superfícies de mesas das salas cirúrgicas analisadas, comprovando a eficácia no processo de controle microbiano.

Consequentemente, as medidas mensuradas pelo ensaio de bioluminescência de ATP nas superfícies de mesas operatórias do CC revelaram que a limpeza e a desinfecção com água ozonizada apresentaram resultados satisfatórios, com baixos rendimentos de RLU. Nesse aspecto, Sanna T, et al. (2018) avaliaram a limpeza de dez salas de cirurgia, em que uma das superfícies amostradas também eram mesas cirúrgicas, usando o ensaio de bioluminescência de ATP, onde os valores de RLU obtidos para todas as amostras foram $32,7 \mathrm{RLU} / 100 \mathrm{~cm}^{2}$ como média geométrica e 29,0 RLU / $100 \mathrm{~cm}^{2}$ como uma mediana, e concluíram que o ensaio de bioluminescência de ATP pode ser uma ferramenta útil para medir a eficiência dos procedimentos de limpeza em ambientes com contagens microbianas baixas, além disso, verificar a qualidade da limpeza apenas pela inspeção visual não fornece dados objetivos e confiáveis a nível de contaminação nosocomial.

Assim, os resultados obtidos nesse atual estudo ilustram a importância de estabelecer e manter um bom processo de limpeza e desinfecção em salas operatórias, visto que o método utilizado para avaliação da desinfecção a partir do uso da água ozonizada não evidenciou contaminação microbiana, pois é uma tecnologia que detecta a presença de ATP na superfície a partir de matérias orgânicas (FERREIRA AM, et al., 2015; FROTA OP, et al., 2020; MASIA MD, et al., 2021). Nascimento EAS, et al. (2021) apontaram que $93,3 \%$ das superfícies de nove salas de cirurgias inspecionadas visualmente foram consideradas limpas, porém, os níveis elevados de trifosfato de adenosina detectaram a presença de microrganismos.

Nesse sentido, a busca por novos agentes antimicrobianos para combater microrganismos presentes em superfícies de ambientes nosocomiais e que não gerem riscos à saúde ocupacional dos envolvidos é fundamental. Ainda que o ozônio tenha grau de toxicidade para olhos e trato respiratório, ele é facilmente detectável devido a seu forte odor característico, além de ser espontaneamente decomposto em gás oxigênio $\left(\mathrm{O}^{2}\right)$ após um curto período de tempo (BOTELHO-ALMEIDA TS, et al., 2018). Em contrapartida, nos serviços de saúde são utilizados diversos produtos para a limpeza e desinfecção de superficies, em que o manejo inadequado dessas substâncias pode provocar impactos ambientais e sérios danos à saúde ocupacional (FREITAS LA, et al., 2019, SATO Y, et al., 2019; CASEY ML, et al., 2017).

Observa-se que esses resultados podem refletir na implementação de melhorias no processo de limpeza e desinfecção da instituição pesquisada, visto que, é um hospital acreditado com excelência, concebido pela Organização Nacional de Acreditação (ONA) e que segue protocolos rígidos voltados para a segurança do 
paciente com objetivo de prevenir infecções relacionadas à assistência à saúde. A rotina de limpeza/desinfecção era efetuada pelo Serviço de Higiene e técnicos de enfermagem após o término dos procedimentos cirúrgicos com a realização de fricção das superfícies para retirar excesso de secreções, limpeza, enxague, secagem e fricção com desinfetantes diretamente na superfície. As mensurações de ATP podem proporcionar avaliação e feedback de resultados com maior sensibilização e colaboração da equipe de limpeza e enfermagem (ELLIMAN WB, et al., 2014; KNAPE L, et al., 2015).

Em síntese, existem algumas limitações e pontos fortes deste estudo que devem ser ressaltados. Como limitações, o tamanho da amostra avaliada e a coleta de dados em uma única instituição de saúde, o que pode generalizar os resultados. No entanto, em relação aos pontos fortes, todas as análises e avaliações das amostras foram realizadas pela mesma pesquisadora e de forma padronizada, assim como as mensurações de RLU na pesquisa, confirmando que o ensaio de bioluminescência de ATP é uma ferramenta objetiva e fácil de usar para a quantificação de matéria orgânica em uma superfície. Apesar das limitações deste estudo, foi possível verificar que o uso da água ozonizada para a desinfecção de superfícies obteve resultados positivos.

\section{CONCLUSÃO}

O uso da água ozonizada demostrou ser uma proposta alternativa e eficaz para desinfecção de superfícies de mesas em SO das cirúrgias ortopédicas e os valores obtidos de RLUs a partir do ensaio de bioluminescência de ATP desempenharam um papel importante na avaliação da atividade antimicrobiana. Ressalta-se a importância de parâmetros adequados no CC, pois pode-se inferir que a longa duração de procedimentos cirúrgicos, assim como a temperatura do ambiente, umidade relativa do ar e o tipo de cirurgia são fatores que favorecem o aumento de riscos as IRAS. Vale ressaltar que os autores estão realizando novas investigações envolvendo os produtos tradicionalmente utilizados nos protocolos de limpeza e desinfecção de superfícies de unidades assistenciais classificada como críticas a assistência à saúde, para a comparação com o uso da água ozonizada com o propósito de definir parâmetros para o atendimento seguro do paciente.

\section{AGRADECIMENTO}

Agradecemos a equipe do Departamento de Ensino e Pesquisa (DEP) da instituição pela parceria e colaboração na realização da pesquisa.

\section{REFERÊNCIAS}

1. ALVIM AL, et al. Monitoramento da limpeza de produtos para saúde com teste adenosina trifosfato. Rev. SOBECC, 2019; 24(2): 57-61.

2. ARKEL AV, et al. Medição de ATP como um método objetivo para medir a contaminação ambiental em 9 hospitais na área da fronteira Holandesa / Belga. Antimicrob Resist Infect Control, 2020; 9(4): 77.

3. BOTELHO-ALMEIDA TS, et al. Avaliação do potencial, aplicabilidade e eficácia do processo de esterilização por ozônio para dispositivos médicos. Journal of Pharmaceutical Innovation, 2018; 13(2): 87-94.

4. AGÊNCIA NACIONAL DE VIGILÂNCIA SANITÁRIA (ANVISA). Critérios Diagnósticos de Infecção Relacionada à Assistência à Saúde. Brasília - DF: Brasil, 2017a. Disponível em: http://www.saude.ba.gov.br/wpcontent/uploads/2019/06/Crit\%C3\%A9rios-Diagnosticos-IRAS-vers\%C3\%A3o-2017.pdf. Acessado em: 05 de dezembro de 2021.

5. AGÊNCIA NACIONAL DE VIGILÂNCIA SANITÁRIA (ANVISA). Medidas de Prevenção de Infecção Relacionada à Assistência à Saúde. Brasília - DF: Brasil, 2017b. Disponível em: http://www.riocomsaude.rj.gov.br/Publico/MostrarArquivo.aspx?C=pCiWUy84\%2BR0\%3D. Acessado em: $07 \mathrm{de}$ novembro de 2021.

6. BRUCE $N$, et al. A alta umidade na sala de operação (OU) afeta as taxas de infecção do local cirúrgico (SSI)? American Journal of Infection Control, 2007; 35(5): 191.

7. CAETANO MH, et al. Ação antimicrobiana do gás ozônio em superfícies e na aeromicrobiota. Acta Paul Enferm, $2021 ; 34$.

8. CASEY ML, et al. Problemas de saúde e exposição a produtos desinfetantes entre a equipe de um grande hospital multiespecializado. American Journal of Infection Control, 2017; 45(10): 1133-1138.

9. DEMIR F, ATGUDEN A. Investigação experimental na inativação microbiana de água potável de poços domésticos usando ozônio sob diferentes condições de tratamento. Ozone-Sci. Eng, 2016; 38: 25-35.

10. DOBEIC, M. Ozônio como desinfetante alternativo na indústria alimentícia. Meso, 2017; 19(4): $346-352$.

11. DRESCH F, et al. Contaminação de superfícies localizadas em unidades de terapia intensiva e salas de cirurgia: uma revisão sistemática da literatura. R Epidemiol Control Infec, Santa Cruz do Sul, 2018; 8(1): 85-91. 
12. ELLIMAN WB, et al. Feedback direto com o luminômetro ATP como ferramenta de melhoria de processos para limpeza de terminais de quartos de pacientes. Am J Infect Control, 2014; 42 (2): 195-7.

13. FENG L, et al. Inativação de Vibrio parahaemolyticus por Ozônio Aquoso. Jornal of Microbiology and Biotechnology, 2018; 28(8): 1233-1246.

14. FERREIRA AM, et al. Avaliação da desinfecção de superfícies hospitalares por diferentes métodos de monitoramento. Rev. Latino-Am. Enfermagem. 2015; 23(3): 466-74.

15. FREITAS LA, et al. Eficácia do hipoclorito de sódio e do álcool $70 \%$ na desinfecção de superfícies: revisão integrativa. Ciência, Cuidado E Saúde, 2019; 18(2).

16. FROTA OP, et al. Eficiência da limpeza e desinfecção de superfícies clínicas: métodos de avaliação. Revista Brasileira de Enfermagem, 2020; 73(1).

17. FURLAN MC, et al. Avaliação da desinfecção de superfícies em ambulatório antes e depois de um programa de intervenção. BMC Infect Dis, 2019; 19(1): 355.

18. GIROTRA R. Uso da metodologia seis sigma para reduzir infecções de sítio cirúrgico em uma creche cirúrgica no norte da Índia. International Journal of Infectious Diseases, 2020; 101(1), 322-323.

19. HAQUE M, et al. Health care-associated infections - an overview. Infect. Drug Resist, 2018; 11: 2321-2333.

20. KNAPE $L$ et al. O método de trifosfato de adenosina como uma ferramenta de controle de qualidade para avaliar a 'limpeza' de superfícies hospitalares tocadas com frequência. J Hosp Infect, 2015; 91(2): 166-70.

21. LIU Z, et al. Influence of air supply velocity and room temperature conditions on bioaerosols distribution in a class I operating room. Building and Environment, 2021; 204.

22. LOPES MS, et al. Disinfection of corrugated tubing by ozone and ultrasound in mechanically ventilated tracheostomized patients. Journal of Hospital Infection, 2015; 90(4): 304-309.

23. LUIGI C. O ozônio poderia ser uma medida de desinfecção eficaz contra o novo coronavírus (SARS-CoV-2)? J Prev Med Hyg, 2020; 61(3).

24. MARTINS RB, et al. SARS-CoV-2 Inactivation by Ozonated Water: A Preliminary Alternative for Environmental Disinfection. Ozone: Science \& Engineering, 2020; 3:108-111.

25. MASIA MD, et al. Bioluminescência de ATP para avaliação da eficácia do procedimento de limpeza manual durante o reprocessamento de instrumentos cirúrgicos reutilizáveis. Saúde (Basel), 2021; 9(3): 352.

26. NASCENTE EP, et al. Potencial antimicrobiano do ozônio: aplicações e perspectivas em medicina veterinária. PUBVET, 2019; 13(9): 130.

27. NASCIMENTO EAS, et al. Avaliação de diferentes métodos de monitoramento de limpeza de superfície em salas de operação. Revista Brasileira de Enfermagem, 2021; 74(3).

28. RAVI B, et al. Surgical duration is associated with an increased risk of periprosthetic infection following total knee arthroplasty: A population-based retrospective cohort study. EClinicalMedicine, 2019; 16: 74-80.

29. REZENDE C, et al. Avaliação microbiológica de superfícies inanimadas no centro cirúrgico de um hospital no noroeste paulista. Revista Brasileira Multidisciplinar, 2018; 21(1): 55-64.

30. ROBAKOWSKA M, et al. Segurança do paciente relacionada à contaminação microbiológica do meio ambiente de um hospital clínico multifuncional. Int J Environ Res Saúde Pública, 2021; 18(7): 3844.

31. SÁNCHEZ GM. Água ozonizada, fundo, usos na medicina e bases pré-clínicas. Spanish Journal of Ozone Therapy, 2019; 9(1): 5-31.

32. SANNA T, et al. Ensaio de bioluminescência ATP para avaliação de práticas de limpeza em salas de cirurgia: aplicabilidade e limitações. BMC Infect Dis, 2018; 18(1): 583.

33. SANTOS PVF, et al. Infecção do sítio cirúrgico em pacientes no pós-operatório de cirurgias ortopédicas eletivas. Revista Interfaces Científicas - Saúde e Ambiente, Aracaju, 2017; 5(2): 71-79.

34. SATO Y, et al. Comparação de vários desinfetantes na atividade bactericida em ambientes contaminados por matéria orgânica. Biocontrol Sci. 2019; 24(2): 103-108.

35. SILVA EN, et al. Fatores de risco para infecção de sítio cirúrgico em cirurgias traumatoortopédicas. Revista Cuidarte, $2021 ; 12(2)$ : e1292.

36. SOUZA MGA, et al. Fatores de interferencia na qualidade da desinfecção e limpeza de superficies hospitalar. Brazilian Journal of Health Review, 2021; 4(2): 8981-8993.

37. SPRUCE L. A limpeza ambiental completa ajuda a prevenir a transmissão de patógenos. AORN J, 2020; 111(6): 708709.

38. TORMIN SC, et al. Análise do efeito bactericida do ozônio sobre bactérias multirresistentes. Arquivos Médicos dos Hospitais e da Faculdade de Ciências Médicas da Santa Casa de São Paulo, 2016; 61: 138-141.

39. WEI C, et al. Ozonização no tratamento de água: a geração, propriedades básicas do ozônio e sua aplicação prática. Reviews in Chemical Engineering, 2017; 33(1): 49-89.

40. WOLLHEIM C, et al. Efeito microbicida do ozônio gasoso em Pseudomonas Aeruginosa, staphylococcus aureus e candida albicans. Rev. Iberoam. Pod - revista eletrônica, 2020; 2(1): 121-125. 